\title{
Cigarette smoking as a risk factor for other substance misuse: 10-year study of individuals with and without attention-deficit hyperactivity disorder
}

Joseph Biederman, Carter R. Petty, Paul Hammerness, Holly Batchelder and Stephen V. Faraone

\section{Background}

We previously documented that cigarette smoking is a risk factor for subsequent alcohol and drug misuse and dependence in adolescent girls with attention-deficit hyperactivity disorder (ADHD).

\section{Aims}

To revisit this hypothesis with a large longitudinal sample of both genders followed up for 10 years into young adulthood.

\section{Method}

We used data from two identically designed, Iongitudinal, case-control family studies of boys and girls with and without ADHD ascertained from psychiatric and paediatric sources. We studied 165 individuals with ADHD and 374 controls followed up longitudinally and masked for 10 years. We assessed ADHD, smoking and substance use status using structured diagnostic interviews. We tested the association between cigarette smoking and subsequent substance use outcomes using cox proportional hazard regression models.

\section{Results}

Youth with ADHD who smoked cigarettes $(n=27)$ were significantly more likely to subsequently develop drug misuse and dependence compared with youth with ADHD who did not smoke $(n=138, P<0.05)$.

\section{Conclusions}

These results confirm that cigarette smoking increases the risk for subsequent drug and alcohol use disorders among individuals with ADHD. These findings have important public health implications, and underscore the already pressing need to prevent smoking in children with ADHD.

\section{Declaration of interest}

J.B. is currently receiving research support from: Elminda,
Janssen, McNeil and Shire. He has received: honoraria from the Massachusetts General Hospital (MGH) Psychiatry Academy for a tuition-funded continuing medical education (CME) course on ADHD; departmental royalties from a copyrighted rating scale used for ADHD diagnoses, paid to the Department of Psychiatry at MGH by Eli Lilly, Shire and AstraZeneca; a speaker's fee for a talk given at Fundación Dr. Manuel Camelo A.C. in Monterrey, Mexico; honoraria for consultations for Shionogi Pharma and Cipher Pharmaceuticals, paid to the Department of Psychiatry at the MGH; research support, consultation fees, or speaker's fees for/from: Abbott, Alza, AstraZeneca, Boston University, Bristol-Myers Squibb, Celltech, Cephalon, Eli Lilly and Co., Esai, Fundacion Areces (Spain), Forest, GlaxoSmithKline, Gliatech, Hastings Center, Janssen, McNeil, Medice Pharmaceuticals (Germany), Merck, MMC Pediatric, NARSAD, NIDA, New River, NICHD, $\mathrm{NIMH}$, Novartis, Noven, Neurosearch, Organon, Otsuka, Pfizer, Pharmacia, Phase V Communications, Physicians Academy, The Prechter Foundation, Quantia Communications, Reed Exhibitions, Shire, the Spanish Child Psychiatry Association, The Stanley Foundation, UCB Pharma, Veritas, and Wyeth. In the past 12 months, P.H. has participated in CME activities/ writing supported by Shire Pharmaceuticals and, as an investigator/principal investigator, in research funded by: Cephalon, Forest, GlaxoSmithKline, Johnson \& Johnson, McNeil, Novartis, Ortho-McNeil Janssen, Shire, Takeda Pharmaceuticals and Elminda. P.H. has also received honoraria from commercial entities supporting the MGH Psychiatry Academy (www. mghcme.org). In the past year, S.V.F. received consulting income and research support from Shire, Otsuka and Alcobra and research support from the National Institutes of Health. He has also received consulting fees or was on advisory boards or participated in CME programmes sponsored by: Shire, McNeil, Janssen, Novartis, Pfizer and Eli Lilly.
Numerous studies have documented that attention-deficit hyperactivity disorder (ADHD) increases the risk for nicotine use across the life cycle. Milberger et al ${ }^{1,2}$ found significant associations between ADHD and cigarette smoking in both referred and non-referred paediatric samples. Those studies documented that ADHD increased the risk for cigarette smoking in early adolescence twofold and was associated with a 2-year earlier age at onset than controls. Likewise, Tercyak et $a l^{3}$ found that adolescents with ADHD were three times more likely to smoke than adolescents without ADHD. Pomerleau et al ${ }^{4}$ documented that adult $\mathrm{ADHD}$ is associated with, and an increased risk for, tobacco addiction and, among smokers, increased difficulty quitting. Glass \& Flory ${ }^{5}$ summarised several possible mechanisms for this relationship, including the self-medication hypothesis and other social, cognitive and psychopathological factors.
The extant literature also supports an association between $\mathrm{ADHD}$ and other substance use disorders (alcohol or drug misuse or dependence) that establishes itself by mid to late adolescence. Milberger et $a l^{6}$ showed that although non-nicotine substance use disorders were not associated with ADHD in early to midadolescence, they were significantly and robustly associated with ADHD by late adolescence. Using two 10-year follow-up studies of ADHD, Wilens and colleagues ${ }^{7}$ found that ADHD was a significant risk factor for the development of substance use disorders and cigarette smoking in both genders. These findings bear remarkable congruence to results from retrospective studies of adults with and without ADHD that show that ADHD is associated with an increased risk for drug and alcohol misuse and dependence substance use disorders that tend to emerge in late adolescence and young adulthood. ${ }^{8,9}$ Taken together these 
findings suggest a temporal relationship between the earlier onset of cigarette smoking in early adolescence and the later onset of drug and alcohol misuse and dependence in later adolescent and young adult years, raising the possibility that cigarette smoking may act as a gateway for the subsequent development of substance use disorders.

The gateway hypothesis was formulated to model how adolescents initiate and progress in the use of various drugs. ${ }^{10}$ The hypothesis states that substance use follows developmental pathways, where cigarettes or alcohol open the door to marijuana use, and marijuana thereupon becomes a gateway to more dangerous and addictive drugs such as cocaine or heroin. Throughout this paper, cigarette smoking as a 'gateway' refers to the increased risk for substance use disorders subsequent to cigarette smoking. Several studies have produced convincing evidence that individuals who smoke cigarettes have an increased likelihood of engaging in other drug use. For example, Torabi et $a l^{11}$ found that individuals who consistently smoked a pack of cigarettes a day were 10 to 30 times more likely than non-smokers to subsequently use drugs and Lai et al $^{12}$ reported that individuals who smoked cigarettes were significantly more likely to have progressed to marijuana, cocaine, crack and heroin use.

We previously reported ${ }^{13}$ in a sample of adolescent girls with and without ADHD, that cigarette smoking significantly increased the risk for subsequent use of alcohol and drugs and that this association was stronger for girls with ADHD relative to controls. These findings suggest a developmental progression for addictive behaviours in ADHD that starts with cigarette smoking in early adolescence and progresses into alcohol and drug misuse or dependence by late adolescence and young adult years. This idea is consistent with the hypothesis that cigarette smoking acts as a gateway. The main goal of this study was therefore to reassess whether cigarette smoking is a gateway for subsequent alcohol and drug misuse and dependence in youth with ADHD who have grown up. Towards this end, we evaluated the risk for substance use disorders in a large longitudinal sample of boys and girls ascertained from psychiatric and paediatric sources with and without ADHD followed up for 10 years into the young adult years stratified by smoking status. We tested the hypothesis that cigarette smoking would increase the risk for subsequent alcohol and drug use disorders by the young adult years and that the magnitude of this association will be stronger in youth with ADHD. To the best of our knowledge this is the first study to assess cigarette smoking as a gateway to substance use disorders in youth with ADHD who have grown up. This follow-up sample is particularly important considering the high prevalence of substance use in young adults.

\section{Method}

\section{Participants}

Detailed study methodology has been previously described. ${ }^{14-17}$ Briefly, participants were derived from two longitudinal casecontrol family genetic study of male and female youth with and without ADHD. The studies consisted of 280 ADHD probands (140 male, 140 female) and 242 controls without ADHD (120 male, 122 female), aged 6-17 at the time of ascertainment. We also included the 317 siblings (179 male, 138 female) of the ADHD probands and the 260 siblings (137 male, 123 female) of the control probands. Male probands and their siblings were assessed at baseline, 1-, 4- and 10-year follow-ups, whereas female probands and their siblings were assessed at baseline, 5- and 11-year follow-ups. Potential participants were excluded if they had been adopted, or if their nuclear family was not available for study. Probands were excluded if they had major sensorimotor disorders (paralysis, deafness, blindness), psychosis, autism, inadequate command of the English language, or a full scale $\mathrm{IQ}^{18}$ less than 80. All of the ADHD probands (ADHD group) met full DSM-III- ${ }^{19}$ diagnostic criteria for ADHD according to clinical assessment at the time of the clinical referral; at the time of recruitment for this study they all had active symptoms of the disorder. After a detailed description of the study procedures, written informed consent was obtained from all participants. For participants younger than 18 , assent was also provided. This study was approved by the institutional review board of the Massachusetts General Hospital.

Psychiatric assessments of participants younger than 18 years relied on the epidemiologic version of the Schedule for Affective Disorders and Schizophrenia for School-Aged Children Epidemiological version (Kiddie-SADS-E). ${ }^{20,21}$ Participants 18 years of age and older were assessed with the Structured Clinical Interview for DSM (SCID) $)^{22,23}$ (supplemented with modules from the Kiddie-SADS-E to assess childhood diagnoses). We interviewed the mothers for all participants and directly interviewed participants older than 12 years. We combined data from direct and indirect interviews by considering a diagnostic criterion positive if it was endorsed in either interview. All assessment personnel were masked to proband diagnosis (ADHD or control) and ascertainment site (psychiatric or paediatric). Parents (522 mothers, 509 mothers) were assessed at baseline with the SCID. Socioeconomic status was measured using the five-point Hollingshead scale. $^{24}$

The interviewers had undergraduate degrees in psychology and were extensively trained. Based on 500 assessments from interviews of children and adults, the median kappa coefficient for diagnoses was 0.98. Kappa coefficients for individual diagnoses included: ADHD (0.88), conduct disorder (1.0), major depression (1.0), mania (0.95), separation anxiety (1.0), agoraphobia (1.0), panic (0.95) and substance use disorder (1.0). We considered a disorder positive if DSM diagnostic criteria were unequivocally met.

A committee of board-certified child and adult psychiatrists who were masked to the participant's ADHD status, referral source and all other data resolved diagnostic uncertainties. Diagnoses presented for review were considered positive only when the committee determined that diagnostic criteria were met to a clinically meaningful degree. We estimated the reliability of the diagnostic review process by computing kappa coefficients of agreement for clinician reviewers. For these diagnoses, the median reliability between individual clinicians and the review committee assigned diagnoses was 0.87 . Kappa coefficients for individual diagnoses included: ADHD (1.0), conduct disorder (1.0), major depression (1.0), mania (0.78), separation anxiety (0.89), agoraphobia (0.80), panic (0.77) and substance use disorder (1.0).

\section{Statistical analyses}

Cigarette smoking was defined as ever having smoked more than three times a week or any regular habit of smoking (e.g. only at parties) for an age at onset before age 18 years. For onset at age 18 years or after, cigarette smoking was defined as smoking every day. For the primary analysis, participants were included if they were reassessed at the 10- or 11-year follow-up. Participants were excluded if they reported an age at onset of any psychoactive substance use disorder at the same age or prior to the age at onset of smoking ( $n=122 ; 47$ with ADHD, 75 without ADHD). This yielded a total of 651 participants. Participants were grouped into four groups according to their ADHD diagnosis at baseline and their lifetime smoking status. We compared the resulting four 
groups on demographic features. We tested the risk of developing psychoactive substance use disorders using Cox proportional hazard models. The reported age at onset was used as the failure time for each substance use disorder.

The secondary analysis used smoking status at the 4- or 5-year follow-up to predict psychoactive substance use disorders (alcohol or drug misuse or dependence) at the 10- or 11-year follow-up, so we did not have to rely on retrospectively reported ages at onset. The secondary analysis was limited to participants who were at least 12 years of age and had no history of psychoactive substance use disorders at the 4- or 5-year follow-up and were reassessed at the 10- or 11-year follow-up $(n=539)$. A total of 112 participants were excluded because they had a substance use disorder at the 4- or 5-year follow-up. Participants were grouped according to their ADHD diagnosis at baseline and their smoking status at the 4- or 5-year follow-up. The same statistical tests were used for the secondary analysis as described for the primary analysis.

For both analyses, we repeated each model controlling for conduct disorder, bipolar disorder or parental substance use disorder (the same disorder as the outcome) to determine whether our findings were independent of these factors. We also tested for any significant interaction effects of smoking status and comorbid disruptive behaviour disorder, mood disorder, or multiple $(\geqslant 2)$ anxiety disorders, proband status or gender. To account for the non-independence of siblings, we used the Huber ${ }^{25}$ correction to produce robust variances for all statistical tests. All tests were two-tailed with alpha set at 0.05 .

\section{Results}

The analysis was restricted to participants that did not report an age at onset for alcohol misuse, alcohol dependence, drug misuse or drug dependence at the same age or before the onset of smoking ( $n=213$ with ADHD, $n=438$ without ADHD). Among these 651 participants, the overall rate of smoking was $28 \%$ (34\% and 25\%, for those in the ADHD group and the control group respectively, $\left.\chi_{(1)}^{2}=6.99, P=0.008\right)$. The average age at smoking onset was significantly earlier in the ADHD group than in the control group (13.9 (s.d.=2.7) v. 15.4 (s.d.=2.7) years of age, $\left.t_{(146)}=-3.64, P<0.001\right)$. Of 181 participants that met criteria for smoking, $89 \%(n=161)$ had an onset before age 18 .

\section{Sociodemographic characteristics}

As presented in Table 1, for our primary analysis the non-smoking participants with ADHD were the youngest, followed by the nonsmokers without ADHD; and the smokers with ADHD, and the smokers without ADHD were the oldest. The non-smoking participants without ADHD had a significantly higher socioeconomic status compared with the other three groups, and the non-smokers with ADHD had a higher socioeconomic status than the smokers with ADHD. In addition, smokers without ADHD had fewer males compared with both ADHD groups. Therefore, socioeconomic status, gender and age at the 11-year follow-up were added as covariates to all subsequent statistical models. For our secondary analysis the demographic characteristics were largely the same, with the exception of no significance difference in gender distribution (Table 1). Therefore, only socioeconomic status and age were added as covariates for the secondary analysis.

\section{Primary analyses: risk of developing substance use disorders}

\section{Alcohol misuse and dependence}

As shown in Fig. 1, although smokers with and without ADHD had a significantly higher risk of developing alcohol misuse compared with non-smokers with and without ADHD, this risk was highest among smokers with ADHD (smokers with ADHD v. non-smokers without ADHD: hazard ratio $(\mathrm{HR})=2.6,95 \%$ CI 1.8-3.8, $z=4.97, P<0.001$; smokers with ADHD v. nonsmokers with ADHD: $\mathrm{HR}=2.3,95 \%$ CI $1.5-3.5, \quad z=3.81$, $P<0.001$; smokers without ADHD $v$. non-smokers without ADHD: $\mathrm{HR}=1.8$ 95\% CI 1.3-2.6, $z=3.34, P=0.001$; smokers without ADHD v. non-smokers with ADHD: $\mathrm{HR}=1.6,95 \% \mathrm{CI}$ $1.04-2.4, z=2.14, P=0.03)$. At the mean age of 23 years, the estimated rate of alcohol misuse was $62 \%$ for smokers with ADHD and $47 \%$ for smokers without ADHD v. $43 \%$ for non-smokers with $\mathrm{ADHD}$ and $31 \%$ for non-smokers without ADHD.

Likewise, although smokers without ADHD had a significantly higher risk for developing alcohol dependence compared with non-smokers without ADHD $\quad(\mathrm{HR}=2.6 \quad 95 \%$ CI $1.4-4.8$, $z=3.15, P=0.002)$, this risk was highest among smokers with ADHD who had a significantly higher risk of developing alcohol dependence compared with the other three groups (non-smokers

Table 1 Demographic features in non-smokers and smokers with and without attention-deficit hyperactivity disorder (ADHD)

\begin{tabular}{|c|c|c|c|c|c|c|c|}
\hline & \multicolumn{2}{|c|}{ Non-smokers } & \multicolumn{2}{|c|}{ Smokers } & \multirow[b]{2}{*}{$F$ (d.f.) } & \multirow[b]{2}{*}{$\chi^{2}$ (d.f.) } & \multirow[b]{2}{*}{$P$} \\
\hline & Without ADHD & With ADHD & Without ADHD & With ADHD & & & \\
\hline \multicolumn{8}{|l|}{ Primary analysis } \\
\hline Total $n$ & 330 & 140 & 108 & 73 & & & \\
\hline \multicolumn{8}{|l|}{ Age, years: mean (s.d.) } \\
\hline Baseline & $12.3(4.9)$ & $10.6(3.4)^{\mathrm{a}}$ & $13.4(4.9)^{b}$ & $11.4(3.3)^{\mathrm{c}}$ & $9.88(3,386)$ & & $<0.001$ \\
\hline 4-year follow-up & $16.5(5.0)$ & $15.1(3.6)^{\mathrm{a}}$ & $17.5(5.1)^{\mathrm{b}}$ & $16.0(3.5)^{\mathrm{C}}$ & $6.74(3,376)$ & & $<0.001$ \\
\hline 11-year follow-up & $23.2(5.1)$ & $21.4(3.7)^{\mathrm{a}}$ & $24.4(5.0)^{a, b}$ & $22.4(3.5)^{\mathrm{b}, \mathrm{c}}$ & $10.71(3,386)$ & & $<0.001$ \\
\hline Male, $n(\%)$ & $160(48)$ & $74(53)$ & $42(39)^{\mathrm{b}}$ & $44(60)^{c}$ & & $9.76(3)$ & 0.02 \\
\hline Baseline SES & $1.5(0.7)$ & $1.8(1.0)^{\mathrm{a}}$ & $1.8(1.0)^{\mathrm{a}}$ & $2.1(1.0)^{\mathrm{a}, \mathrm{b}}$ & & $25.73(3)$ & $<0.001$ \\
\hline \multicolumn{8}{|l|}{ Secondary analysis } \\
\hline Total $n$ & 326 & 138 & 48 & 27 & & & \\
\hline \multicolumn{8}{|l|}{ Age, years: mean (s.d.) } \\
\hline Baseline & $12.8(4.7)$ & $10.6(2.9)^{a}$ & $14.9(4.9)^{a, b}$ & $12.5(2.9)^{b, c}$ & $16.70(3,327)$ & & $<0.001$ \\
\hline 4-year follow-up & $17.1(4.7)$ & $15.1(3.1)^{\mathrm{a}}$ & $19.2(4.8)^{a, b}$ & $16.7(2.8)^{b, c}$ & $15.09(3,327)$ & & $<0.001$ \\
\hline 11-year follow-up & $23.8(4.8)$ & $21.5(3.2)^{a}$ & $25.8(5.0)^{a, b}$ & $23.4(2.9)^{b, c}$ & $16.74(3,327)$ & & $<0.001$ \\
\hline Male, $n(\%)$ & $151(46)$ & $75(54)$ & $20(42)$ & $17(63)$ & & $5.90(3)$ & 0.12 \\
\hline Baseline SES, mean (s.d.) & $1.5(0.8)$ & $1.8(0.9)^{\mathrm{a}}$ & $1.9(0.8)^{a}$ & $2.1(1.0)^{\mathrm{a}}$ & & $22.12(3)$ & $<0.001$ \\
\hline $\begin{array}{l}\text { SES, socioeconomic status. } \\
\text { a. } P<0.05 \text { V. non-smokers wit } \\
\text { b. } P<0.05 \text { V. non-smokers wit } \\
\text { c. } P<0.05 \text { V. smokers without }\end{array}$ & & & & & & & \\
\hline
\end{tabular}


(a)

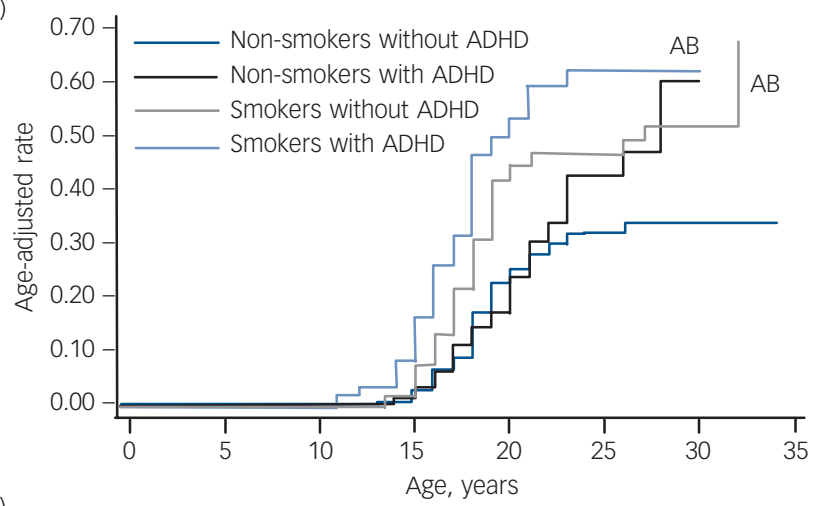

(C)

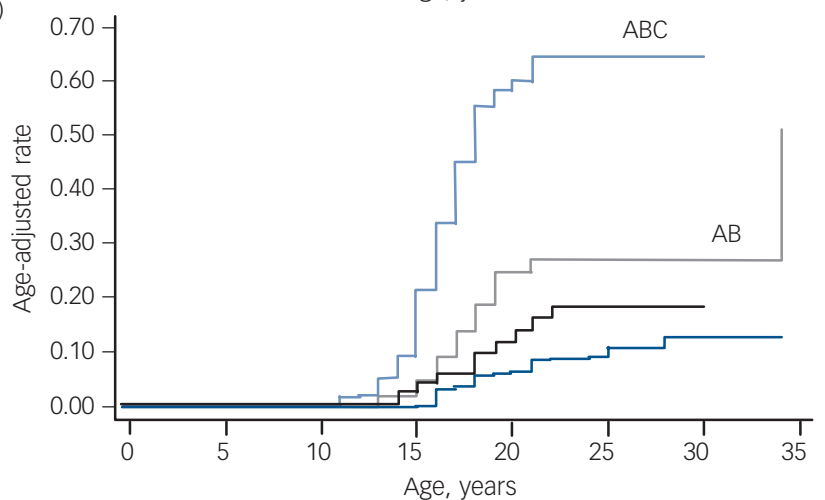

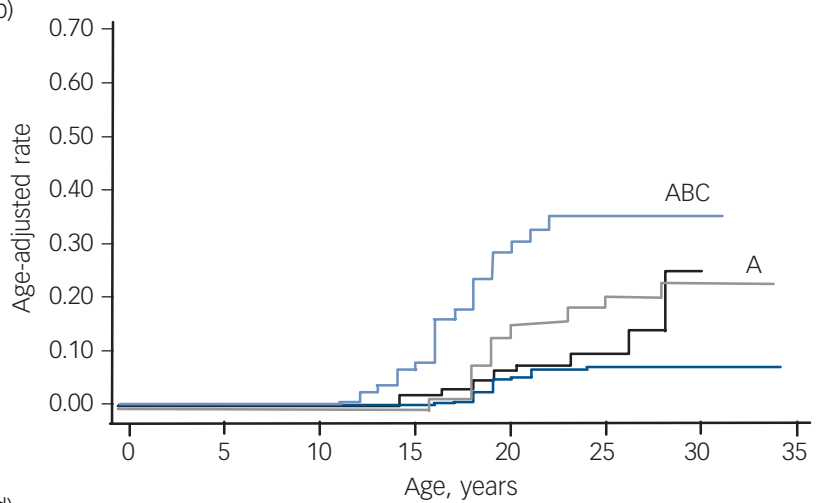

(d)

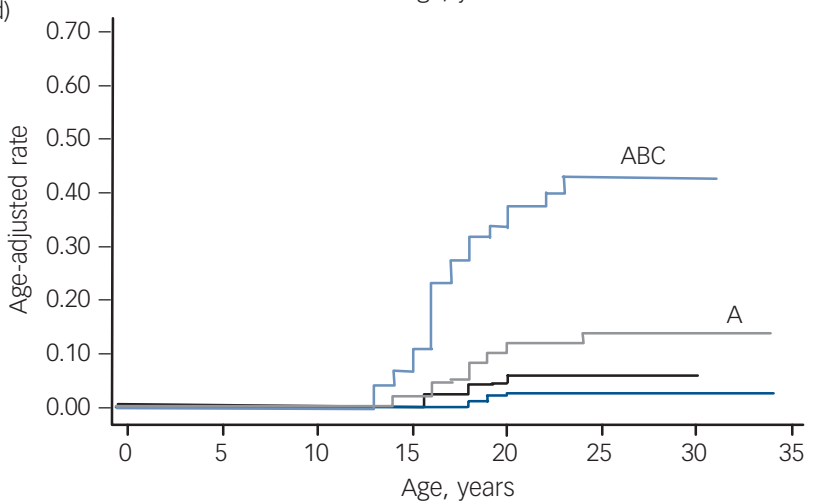

Fig. 1 Risk for psychoactive substance use disorder in smokers and non-smokers with and without attention-deficit hyperactivity disorder (ADHD): primary analysis. (a) Risk for alcohol misuse, (b) risk for alcohol dependence, (c) risk for drug misuse, (d) risk for drug dependence.

$A, P<0.05$ v. non-smokers without ADHD; $B, P<0.05$ v. non-smokers with $A D H D ; C, P<0.05$ v. smokers with ADHD.

without ADHD: $\mathrm{HR}=6.1,95 \%$ CI $3.3-11.2, z=5.84, P<0.001$; non-smokers with ADHD: $\mathrm{HR}=3.8,95 \%$ CI 1.9-7.5, $z=3.75$, $P<0.001$; smokers without ADHD: $\mathrm{HR}=2.3,95 \%$ CI $1.3-4.2$, $z=2.70, P=0.007)$. Estimated rates of alcohol dependence at age 23 were $7 \%$ for non-smokers without ADHD, $10 \%$ for nonsmokers with ADHD, $18 \%$ for smokers without ADHD and $35 \%$ for smokers with ADHD.

There were no significant interaction effects of ADHD and smoking status predicting alcohol use disorders. As Table 2 shows, independent of ADHD, smoking significantly increased the risk for alcohol misuse and dependence and, independent of smoking, ADHD significantly increased the risk for alcohol dependence.

\section{Drug misuse and dependence}

Although smokers with and without ADHD had a significantly higher risk of developing drug misuse compared with the nonsmoking groups (non-smokers without ADHD: HR=3.1, 95\% CI $1.8-5.4, \quad z=4.20, \quad P<0.001$; non-smokers with ADHD: $\mathrm{HR}=1.8,95 \%$ CI 1.03-3.3, $z=2.05, P=0.04)$, this risk was highest among smokers with ADHD compared with all other groups (non-smokers without ADHD: HR=9.6, 95\% CI 5.8-15.9, $z=8.76, P<0.001$; non-smokers with ADHD: $\mathrm{HR}=5.6,95 \% \mathrm{CI}$ 3.3-9.3, $z=6.59, P<0.001$; smokers without ADHD: $\mathrm{HR}=3.1$, 95\% CI 1.8-5.1, $z=4.30, P<0.001)$. Estimated rates of drug misuse at age 23 were $9 \%$ for non-smokers without ADHD, $18 \%$ for non-smokers with ADHD, $27 \%$ for smokers without ADHD and 65\% for smokers with ADHD.

Similar results were observed for drug addiction. Smokers with and without ADHD had a significantly higher risk for drug dependence compared with the other three groups ( $v$. non-smokers without ADHD: $\mathrm{HR}=16.5,95 \%$ CI 7.0-39.1, $z=6.37, P<0.001$; v. non-smokers with ADHD: $\mathrm{HR}=7.7,95 \%$ CI 3.3-17.8, $z=4.71, P<0.001 ; v$. smokers without ADHD: HR=4.1, 95\% CI $2.0-8.3, z=3.91, P<0.001)$, this risk was highest among smokers with ADHD. Smokers with ADHD had an estimated drug dependence rate of $43 \%$, compared with $3 \%$ for non-smokers without ADHD, 6\% for non-smokers with ADHD, and 11\% for smokers without ADHD.

\section{Confounders and interaction effects}

All findings remained significant after controlling for the same parental substance use disorder. There were no significant interaction effects of smoking status and comorbid disruptive behaviour disorder, mood disorders, multiple $(\geqslant 2)$ anxiety disorders, proband status or gender when predicting any of the psychoactive substance use disorders (all $P>0.05$ ). However, the alcohol dependence finding between the smokers with and without ADHD lost significance after controlling for conduct disorder or bipolar disorder (both $P>0.05$ ).

\section{Secondary analyses: \\ risk of developing substance use disorders}

To get a clearer longitudinal perspective, we repeated the analysis by restricting the sample to participants that were at least 12 years of age and did not meet criteria for alcohol misuse, alcohol dependence, drug misuse or drug dependence at the 4-year follow-up ( $n=165$ with ADHD, $n=374$ without ADHD). Despite more limited power, results from these secondary analyses were generally consistent with the previous analysis, with the strongest findings being for cigarette smoking increasing the risk for drug 


\begin{tabular}{|c|c|c|c|c|c|c|}
\hline & ADHD, HR (95\% Cl) & z-statistic & $P$ & Smoking, HR (95\% Cl) & z-statistic & $P$ \\
\hline \multicolumn{7}{|l|}{$\begin{array}{l}\text { Primary analysis } \\
\text { Alcohol }\end{array}$} \\
\hline Misuse & $1.3(0.96-1.7)$ & 1.66 & 0.10 & $2.0(1.5-2.6)$ & 4.91 & $<0.001$ \\
\hline Dependence & $2.0(1.2-3.2)$ & 2.82 & 0.005 & $3.1(2.0-4.9)$ & 4.91 & $<0.001$ \\
\hline \multicolumn{7}{|l|}{ Drug } \\
\hline Misuse & $2.4(1.6-3.6)$ & 4.44 & $<0.001$ & $4.2(2.9-6.0)$ & 7.90 & $<0.001$ \\
\hline Dependence & $3.4(1.9-6.1)$ & 4.07 & $<0.001$ & $5.8(3.1-10.9)$ & 5.44 & $<0.001$ \\
\hline \multirow{2}{*}{\multicolumn{7}{|c|}{$\begin{array}{l}\text { Secondary analysis } \\
\text { Alcohol }\end{array}$}} \\
\hline & & & & & & \\
\hline Misuse & $1.4(1.02-1.9)$ & 2.12 & 0.03 & $1.4(0.9-2.1)$ & 1.63 & 0.10 \\
\hline Dependence & $2.0(1.1-3.4)$ & 2.40 & 0.02 & $2.1(1.2-3.7)$ & 2.61 & 0.009 \\
\hline \multicolumn{7}{|l|}{ Drug } \\
\hline Misuse & $1.4(0.9-2.1)$ & 1.67 & 0.09 & $2.5(1.6-4.1)$ & 3.83 & $<0.001$ \\
\hline Dependence & $1.5(0.8-2.8)$ & 1.30 & 0.19 & $3.1(1.7-5.8)$ & 3.68 & $<0.001$ \\
\hline
\end{tabular}

dependence (Fig. 2). Smokers with ADHD had a significantly higher risk for drug dependence compared with the other three groups ( $v$. non-smokers without ADHD: $\mathrm{HR}=5.6$, 95\% CI 2.512.7, $z=4.12, P<0.001 ; v$. non-smokers with ADHD: $\mathrm{HR}=5.4$, 95\% CI 2.2-13.5, $z=3.65, P<0.001 ; v$. smokers without ADHD: $\mathrm{HR}=3.1,95 \%$ CI 1.1-8.7, $z=2.15, \quad P=0.03)$. Smokers with ADHD had an estimated drug dependence rate of $34 \%$, compared with $5 \%$ for non-smokers without ADHD, $8 \%$ for non-smokers with ADHD, and $10 \%$ for smokers without ADHD. All findings remained significant after controlling for the same parental substance use disorder. However, after controlling for conduct disorder and bipolar disorder, the smokers with ADHD remained at higher risk for drug dependence compared with non-smokers with ADHD, but lost significance compared with smokers without ADHD (both $P>0.30$ ) and non-smokers without ADHD (conduct disorder only, $P=0.30$ ). There were no significant interaction effects of smoking status and comorbid disruptive behaviour disorder, mood disorder or multiple $(\geqslant 2)$ anxiety disorders, proband status or gender when predicting any of the psychoactive substance use disorders (all $P>0.05$ ). Using the binary predictor approach, smoking significantly increased the risk of alcohol dependence, drug misuse and drug dependence independently of ADHD (Table 2). Attention-deficit hyperactivity disorder significantly increased the risk for alcohol misuse and dependence independently of smoking.

\section{Discussion}

Whether tobacco is a gateway for subsequent alcohol and drug misuse and dependence in youth with ADHD has major clinical, scientific and public health implications. If confirmed, such findings could help clinicians identify youth with ADHD at high risk for addictive behaviours. If cigarette smoking occurs first in the developmental trajectory of substance use disorders, it would suggest that the prevention of smoking could interrupt the pathway towards alcohol and drug use disorders, which would reduce their associated morbidity, mortality and cost to society. Furthermore, considering that the average age at onset of ADHD is in the pre-school years and the average age at onset of cigarette smoking is in early adolescence, there is an approximate 10-year window for the development of disorder-specific preventive and early intervention strategies to avert tobacco addiction outcomes in youth with ADHD. Scientifically, information about developmental trajectories of substance use disorders may yield new insights into the neurobiology of addictions.

\section{Main findings}

In this large, prospective, controlled study of youth with and without ADHD of both genders followed up into young adulthood, we found that smoking greatly and significantly increased the risk for the subsequent development of alcohol and drug misuse and dependence. Because the risk for substance use disorders afforded by smoking was additive with the risk afforded by ADHD, smokers with ADHD are at especially high risk for substance use disorders. These findings have important public health significance within and without the context of ADHD for the development of preventive and early intervention approaches aimed at mitigating smoking initiation within and without the context of ADHD.

These findings confirm and extend previous results documented in a sample of adolescent girls with and without $\mathrm{ADHD}^{13}$ and provide further support for the hypothesis that cigarette smoking is a gateway for the subsequent development of drug misuse and dependence. These findings indicate that cigarette smoking may help identify a subgroup of youth with ADHD at the highest risk to progress into addictions and support efforts aimed at diminishing the risk for smoking initiation in children with ADHD. Results from our primary analysis indicate that youth with ADHD who smoke cigarettes have a fivefold higher risk for developing alcohol dependence and a ninefold higher risk for developing drug dependence compared with youth without ADHD who do not smoke cigarettes.

Our findings indicate that cigarette smoking is not the only pathway to substance use disorders. A sizeable minority (16\%) of the original group had used drugs before or at the same age that they started smoking. Additionally, some participants developed a substance use disorder and never reported cigarette smoking. Therefore, cigarette smoking should not be viewed as a sufficient or necessary explanation for substance misuse problems, but rather as one of several possible risk factors for subsequent substance use disorders.

Our finding that cigarette smoking is associated with subsequent substance use disorders is consistent with the gateway effect of cigarettes previously documented in the literature. For example, Merrill and colleagues, ${ }^{26}$ analysing data from the 1995 Youth Risk Behavior Survey, found that among high-school seniors, cigarette use before age 13 was associated with a 
(a)
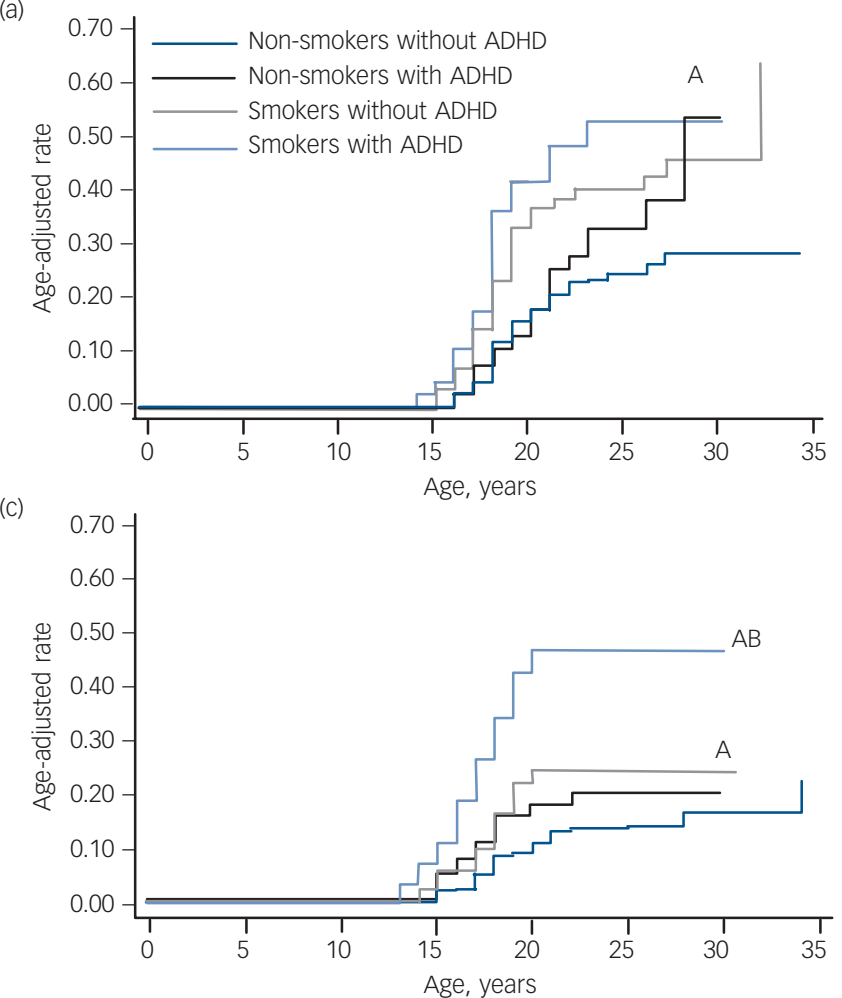

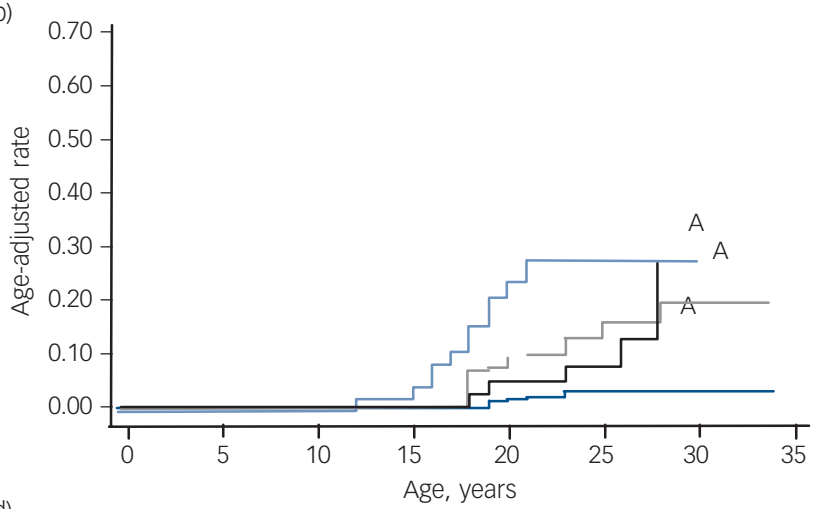

(d)

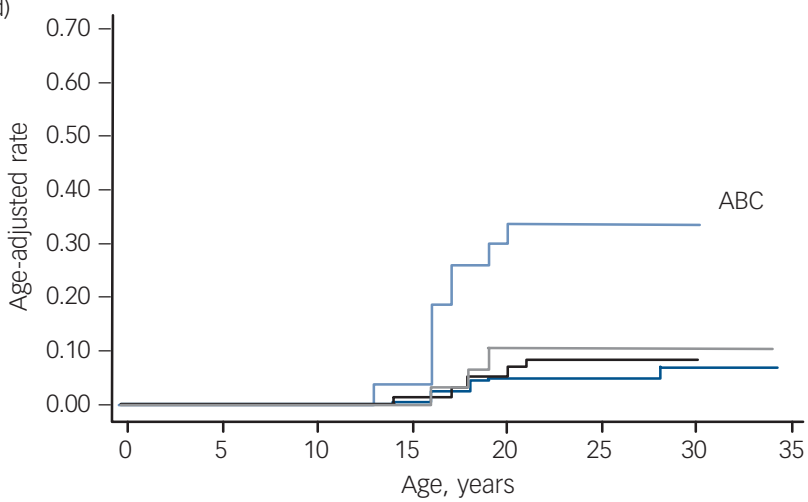

Fig. 2 Risk for psychoactive substance use disorder in smokers and non-smokers with and without attention-deficit hyperactivity disorder (ADHD): secondary analysis. (a) Risk for alcohol misuse, (b) risk for alcohol dependence, (c) risk for drug misuse, (d) risk for drug dependence.

A, $P<0.05 \mathrm{~V}$. non-smokers without ADHD; $B, P<0.05 \mathrm{~V}$. non-smokers with $\mathrm{ADHD} ; \mathrm{C}, P<0.05 \mathrm{~V}$. smokers with ADHD.

significant threefold increased risk for marijuana use. A study analysing the data from the National Household Survey on Drug Misuse also found significant associations between cigarette use and the subsequent use of cocaine, heroin, crack and marijuana. ${ }^{12}$ In another study of this data-set, Wagner \& Anthony ${ }^{27}$ found that youth who had used tobacco or alcohol were more likely to later experience an opportunity to use marijuana and more likely to actually use it given that an opportunity had occurred. Other studies also found that regular smoking was a risk factor for the use of alcohol and other drugs. ${ }^{11,28}$

Our findings show that smokers with ADHD carry two independent and additive risks for subsequent substance use disorders. This finding is consistent with mounting evidence that $\mathrm{ADHD}$ is a significant risk factor for cigarette smoking ${ }^{3-5}$ and for alcohol and drug misuse and dependence. ${ }^{729-31}$ Although ADHD also increased the risk of substance use disorders (independent of the risk afforded by smoking), having ADHD did not potentiate the gateway effect of smoking (i.e. we found no interactions between $\mathrm{ADHD}$ and smoking in predicting subsequent substance use disorders). This suggests that treatment programmes aimed at preventing substance use disorders in youth with ADHD should incorporate interventions for ADHD symptoms, interventions for smoking behaviour among smokers, and preventive interventions for non-smokers.

The reasons why cigarette smoking functions as a gateway for the subsequent use of alcohol and drugs are not entirely clear. Several explanations can be considered. Nicotine modulates dopaminergic activity in the mesolimbic system, ${ }^{32-36}$ which could provide positive reinforcement for other addictive behaviours. ${ }^{37}$ This nicotinic effect could be magnified and be particularly strong in the context of ADHD by the pre-existing dopaminergic abnormalities associated with $\mathrm{ADHD}$, leading to the increased magnitude of effect seen in participants with ADHD in our results. More work is needed to substantiate these intriguing hypotheses.

\section{Implications}

Irrespective of the reasons why cigarette smoking functions as a gateway for the subsequent use of alcohol and drugs, it is important to note that cigarette smoking, alcohol and drugs are major sources of morbidity and mortality in our society and across the world. In the year 2000, at least 435000 US residents died directly as a consequence of tobacco, 85000 as a consequence of alcohol consumption and 17000 as a consequence of drug use. $^{38}$ Because the majority of smokers begin smoking in adolescence, typically by age 12 , cigarette smoking ${ }^{39,40}$ can be targeted for preventive and early intervention efforts. Preventive measures are particular important given the considerable evidence that earlier age of first use of alcohol and drugs is associated with poorer outcomes. ${ }^{10}$

Considering that ADHD significantly increases the risks for both cigarette smoking ${ }^{3,29}$ and alcohol and drug misuse and dependence, ${ }^{6-9}$ if smoking could be prevented in youth with ADHD, a large amount of morbidity and mortality associated with tobacco, alcohol and drugs could be prevented. In a clinical trial examining the effects of bupropion for the prevention of smoking in youth with ADHD, we found that, although treatment with bupropion was ineffective in achieving this goal, adolescents treated with stimulants had a significantly decreased risk for smoking when compared with those that did not receive stimulant treatment. ${ }^{41}$ Similar findings had been reported by Whalen et a $l^{42}$ in a community sample of adolescents with ADHD, who found that participants receiving pharmacotherapy for ADHD smoked 
significantly less than those who went untreated. Similar results were also documented in naturalistic samples. These studies showed that treatment with stimulants decreased the elevated risk for smoking in youth with ADHD to population rates. ${ }^{43,44}$ Most recently, Gehricke et $a l^{45}$ found that medication for ADHD reduced cotinine levels and withdrawal in smokers with ADHD. If confirmed, these findings would have a large public health impact.

\section{Limitations}

Although our results are consistent with the gateway hypothesis, they could also be accounted for by the alternate idea that genetic risk, environmental exposures or a combination of these factors predispose youth to using substances in general, including both nicotine and other drugs. In this model, the use of one substance (such as nicotine) does not causally affect the subsequent use of other substances (such as alcohol). For example, family and twin studies suggest that there is some shared heritability among smoking and substance use disorders. ${ }^{46,47}$ The relative ease of access and availability to cigarettes would explain the observed temporal sequence of nicotine use followed by the use of other substances. Nevertheless, at the very least, our results provide valuable clinical information by identifying a strong risk factor (i.e. smoking) for future alcohol and drug use, misuse and dependence, especially in youth with ADHD.

Our results should be considered in the light of some methodological limitations. This was a secondary analysis of two longitudinal family-genetic studies of ADHD. Studies specifically designed to test the gateway hypothesis of cigarette smoking should seek to replicate our findings. Our sample was predominantly White and the probands were referred for ADHD. As such, our findings may not generalise to community samples and ethnic minorities. Future studies should attempt to replicate these findings in community samples. Another constraint on our generalisability is the limited range of socioeconomic status in our sample. Although all five of the Hollingshead categories were represented in our sample, very few participants were in the lowest categories. Also, the size of our smoking sample was relatively small. Although the results were mostly significant nonetheless, replication in a larger sample would be beneficial.

Also, we depended on the retrospectively reported ages at onset for smoking and substance use to establish the temporal sequence of smoking as an exposure. To the degree that these ages were incorrectly recalled, our results may suffer from misclassification and thus a reduction in precision. However, although the exact ages may not have been recalled accurately, the relative ordering of the ages of smoking and substance use initiation are likely to be correct, so that any misclassification of our exposure and outcome variables should be minimal. Also, there may be additional, unmeasured confounders that may account for our findings. Although it is unlikely that an unmeasured confounder could account for the magnitude of effect found here, future studies should include other predictors of adolescent substance use. Given that $16 \%$ of our original sample developed cigarette smoking at the same age or after substance use disorders, other studies should explore other possible developmental pathways. Although we did not find significant interaction effects of ADHD and cigarette smoking, the very high rates of drug misuse and dependence seen in the failure curves of the smokers with ADHD highlight the possibility that the risk conferred by cigarette smoking is much greater in the context of ADHD. Future studies should explore this possible interaction effect.

Despite these considerations, our results provide further support for cigarette smoking being a risk factor for the subsequent development of alcohol and drug misuse and dependence and that this risk adds to the risk imparted by ADHD. Thus, smokers with ADHD are at especially high risk for substance use disorders and they should be a focus for preventive interventions. These findings have important public health significance within and without the context of ADHD for the development of preventive and early intervention approaches aimed at mitigating smoking initiation within and without the context of ADHD.

Joseph Biederman, MD, Department of Psychiatry, Massachusetts General Hospital and Harvard Medical School, Boston, Massachusetts; Carter R. Petty, MA Paul Hammerness, MD, Holly Batchelder, BS, Department of Psychiatry, Massachusetts General Hospital, Boston, Massachusetts; Stephen v. Faraone, PhD, Department of Psychiatry, SUNY Upstate Medical University, Syracuse, New York, USA

Correspondence: Joseph Biederman, Massachusetts General Hospital, Pediatric Psychopharmacology Program, Yawkey 6A, 55 Fruit Street, Boston, MA 02114, USA. Email: jbiederman@partners.org

First received 28 Jul 2011, final revision 18 May 2012, accepted 14 June 2012

\section{Funding}

This work was supported, in part, by USPHS (NIMH) grant R01 MH-41314-01A2 (JB) and the Pediatric Psychopharmacology Council Fund.

\section{References}

1 Milberger S, Biederman J, Faraone SV, Chen L, Jones J. Attention deficit hyperactivity disorder is associated with early initiation of cigarette smoking in children and adolescents. J Am Acad Child Adolesc Psychiatry 1997; 36: $37-44$.

2 Milberger S, Biederman J, Faraone S, Chen L, Jones J. Further evidence of an association between attention-deficit/hyperactivity disorder and cigarette smoking: findings from a high-risk sample of siblings. Am J Addict 1997; 6 : 205-17.

3 Tercyak KP, Lerman C, Audrain J. Association of attention-deficit/ hyperactivity disorder symptoms with levels of cigarette smoking in a community sample of adolescents. J Am Acad Child Adolesc Psychiatry 2002; 41: 799-805.

4 Pomerleau O, Downey K, Stelson F, Pomerleau C. Cigarette smoking in adult patients diagnosed with attention deficit hyperactivity disorder. J Subst Abuse 1995; 7: 373-8.

5 Glass K, Flory K. Why does ADHD confer risk for cigarette smoking? A review of psychosocial mechanisms. Clin Child Fam Psychol Rev 2010; 13: 291-313.

6 Milberger S, Biederman J, Faraone S, Wilens T, Chu M. Associations between ADHD and psychoactive substance use disorders: findings from a longitudinal study of high-risk siblings of ADHD children. Am J Addict 1997; 6: 318-29.

7 Wilens TE, Martelon M, Joshi G, Bateman C, Fried R, Petty C, et al. Does ADHD predict substance-use disorders? A 10-year follow-up study of young adults with ADHD. J Am Acad Child Adolesc Psychiatry 2011; 50: 543-53.

8 Biederman J, Faraone SV, Monuteaux MC, Spencer T, Wilens T, Bober M, et al. Gender effects of attention deficit hyperactivity disorder in adults, revisited. Biol Psychiatry 2004; 55: 692-700.

9 Mannuzza S, Klein R, Bessler A, Malloy P, LaPadula M. Adult psychiatric status of hyperactive boys grown up. Am J Psychiatry 1998; 155: 493-8.

10 Kandel D. Stages and Pathways of Drug Involvement: Examining the Gateway Hypothesis. Cambridge University Press, 2002.

11 Torabi MR, Bailey WJ, Majd-Jabbari M. Cigarette smoking as a predictor of alcohol and other drug use by children and adolescents: evidence of the 'gateway drug effect'. J Sch Health 1993; 63: 302-6.

12 Lai S, Lai H, Page JB, McCoy CB. The association between cigarette smoking and drug abuse in the United States. J Addict Dis 2000; 19: 11-24.

13 Biederman J, Monuteaux M, Mick E, Wilens T, Fontanella J, Poetzl KM, et al. Is cigarette smoking a gateway drug to subsequent alcohol and illicit drug use disorders? A controlled study of youths with and without ADHD. Biol Psychiatry 2006; 59: 258-64.

14 Biederman J, Faraone SV, Mick E, Williamson S, Wilens TE, Spencer TJ, et al. Clinical correlates of ADHD in females: findings from a large group of girls ascertained from pediatric and psychiatric referral sources. J Am Acad Child Adolesc Psychiatry 1999; 38: 966-75. 
15 Biederman J, Faraone S, Milberger S, Guite J, Mick E, Chen L, et al. A prospective 4-year follow-up study of attention-deficit hyperactivity and related disorders. Arch Gen Psychiatry 1996; 53: 437-46.

16 Biederman J, Monuteaux M, Mick E, Spencer T, Wilens T, Silva J, et al. Young adult outcome of attention deficit hyperactivity disorder: a controlled 10 year prospective follow-up study. Psychol Med 2006; 36: 167-79.

17 Biederman J, Petty CR, Monuteaux MC, Fried R, Byrne D, Mirto T, et al. Adult psychiatric outcomes of girls with attention deficit hyperactivity disorder: 11-year follow-up in a longitudinal case-control study. Am J Psychiatry 2010; 167: 409-17.

18 Wechsler D. Manual for the Wechsler Intelligence Scale for Children-Revised. The Psychological Corporation, 1974.

19 American Psychiatric Association. Diagnostic and Statistical Manual of Mental Disorders (3rd edn, revised) (DSM-III-R). APA, 1987.

20 Orvaschel $\mathrm{H}$. Psychiatric interviews suitable for use in research with children and adolescents. Psychopharmacol Bull 1985; 21: 737-45.

21 Orvaschel H. Schedule for Affective Disorder and Schizophrenia for SchoolAge Children Epidemiologic Version. Nova Southeastern University, Center for Psychological Studies, 1994

22 Spitzer RL, Williams JB, Gibbon M, First MB. Structured Clinical Interview for DSM-III-R: Non-Patient Edition (SCID-NP, Version 1.0). American Psychiatric Press, 1990.

23 First M, Spitzer R, Gibbon M, Williams J. Structured Clinical Interview for DSM-IV Axis I Disorders. American Psychiatric Press, 1997.

24 Hollingshead AB. Four Factor Index of Social Status. Yale Press, 1975.

25 Huber PJ. The behavior of maximum likelihood estimates under nonstandard conditions. Proc Fifth Berkeley Symp Math Statist Prob 1967; 1: 221-33.

26 Merrill JC, Kleber HD, Shwartz M, Liu H, Lewis SR. Cigarettes, alcohol, marijuana, other risk behaviors, and American youth. Drug Alcohol Depend 1999; 56: 205-12.

27 Wagner FA, Anthony JC. Into the world of illegal drug use: exposure opportunity and other mechanisms linking the use of alcohol, tobacco, marijuana, and cocaine. Am J Epidemiol 2002; 155: 918-25.

28 Hanna EZ, Yi HY, Dufour MC, Whitmore CC. The relationship of early-onset regular smoking to alcohol use, depression, illicit drug use, and other risky behaviors during early adolescence: results from the youth supplement to the third national health and nutrition examination survey. J Subst Abuse 2001; 13: 265-82.

29 Molina B, Pelham W. Childhood predictors of adolescent substance use in a longitudinal study of children with ADHD. J Abnorm Psychol 2003; 112 497-507.

30 Murphy K, Barkley RA. Attention deficit hyperactivity disorder adults: comorbidities and adaptive impairments. Compr Psychiatry 1996; 37 393-401.

31 Wilens TE, Biederman J, Mick E, Faraone SV, Spencer T. Attention deficit hyperactivity disorder (ADHD) is associated with early onset substance use disorders. J Nerv Ment Dis 1997; 185: 475-82.
32 US Department of Health \& Human Services. Youth Risk Behavior Surveillance - United States, 1999. Centers for Disease Control and Prevention, 2000.

33 Clarke P. Dopaminergic mechanisms in the locomotor stimulant effects of nicotine. Biochem Pharmacol 1990; 42: 595-6.

34 Pich E, Pagliusi S, Tessari M, Talabot-Ayer D, Hooft van Huijsduijnen R, Chiamulera C. Common neural substrates for the addictive properties of nicotine and cocaine. Science 1997; 275: 83-5.

35 Shadel WG, Shiffman S, Niaura R, Nichter M, Abrams DB. Current models of nicotine dependence: what is known and what is needed to advance understanding of tobacco etiology among youth. Drug Alcohol Depend 2000; 59 (suppl 1): S9-22.

36 Brody AL, Mandelkern MA, Jarvik ME, Lee GS, Smith EC, Huang JC, et al. Differences between smokers and nonsmokers in regional gray matter volumes and densities. Biol Psychiatry 2004; 55: 77-84.

37 Lindsay GB, Rainey J. Psychosocial and pharmacologic explanations of nicotine's 'gateway drug' function. J Sch Health 1997; 67: 123-6.

38 Mokdad AH, Marks JS, Stroup DF, Gerberding JL. Actual causes of death in the United States, 2000. JAMA 2004; 291: 1238-45.

39 Sims TH. From the American Academy of Pediatrics: technical reporttobacco as a substance of abuse. Pediatrics 2009; 124: e1045-53.

40 Collins CC, Epstein DH, Parzynski CS, Zimmerman D, Moolchan ET, Heishman SJ. Puffing behavior during the smoking of a single cigarette in tobacco-dependent adolescents. Nicotine Tob Res 2010; 12: 164-7.

41 Monuteaux MC, Spencer TJ, Faraone SV, Wilson AM, Biederman J. A randomized, placebo-controlled clinical trial of bupropion for the prevention of smoking in children and adolescents with attention-deficit/ hyperactivity disorder. J Clin Psychiatry 2007; 68: 1094-101.

42 Whalen CK, Jamner LD, Henker B, Gehricke JG, King PS. Is there a link between adolescent cigarette smoking and pharmacotherapy for ADHD? Psychol Addict Behav 2003; 17: 332-5.

43 Biederman J, Monuteaux MC, Spencer T, Wilens TE, Macpherson HA, Faraone SV. Stimulant therapy and risk for subsequent substance use disorders in male adults with ADHD: a naturalistic controlled 10-year follow-up study. Am J Psychiatry 2008; 165: 597-603.

44 Biederman J, Monuteaux MC, Spencer T, Wilens TE, Faraone SV. Do stimulants protect against psychiatric disorders in youth with ADHD? A 10-year follow-up study. Pediatrics 2009; 124: 71-8.

45 Gehricke JG, Hong N, Wigal TL, Chan V, Doan A. ADHD medication reduces cotinine levels and withdrawal in smokers with ADHD. Pharmacol Biochem Behav 2011; 98: 485-91.

46 Bierut L, Dinwiddie S, Begleiter H, Crowe R, Hesselbrock V, Nurnberger J, et al. Familial transmission of substance dependence: alcohol, marijuana, cocain, and habitual smoking. Arch Gen Psychiatry 1998; 55: 982-8.

47 Merikangas K, Stolar M, Stevens D, Goulet J, Preisig M, Fenton B, et al. Familial transmission of substance use disorders. Arch Gen Psychiatry 1998; 55: 973-9. 